\title{
Age-Related Changes in the Circadian System Unmasked by Constant Conditions ${ }^{1,2,3}$
}

\author{
(1)Takahiro J. Nakamura, ${ }^{1,2,3}$ (D) Wataru Nakamura, ${ }^{4}$ (i) Isao T. Tokuda, ${ }^{5}$ Takahiro Ishikawa, ${ }^{2}$ Takashi \\ Kudo, ${ }^{3}$ Christopher S. Colwell, ${ }^{3}$ and Gene D. Block ${ }^{3}$
}

\section{DOI:http://dx.doi.org/10.1523/ENEURO.0064-15.2015}

${ }^{1}$ Department of Life Sciences, School of Agriculture, Meiji University, Kanagawa, Kawasaki 214-8571, Japan, ${ }^{2}$ Faculty of Pharmaceutical Sciences, Teikyo Heisei University, Tokyo 164-8530, Japan, ${ }^{3}$ Department of Psychiatry and Biobehavioral Sciences, University of California, Los Angeles, Los Angeles, California 90024-1759, ${ }^{4}$ Laboratory of Oral Chronobiology, Graduate School of Dentistry, Osaka University, Suita, Osaka 565-0871, Japan, and ${ }^{5}$ Department of Mechanical Engineering, Ritsumeikan University, Shiga, Kusatsu 525-8577, Japan

\begin{abstract}
Circadian timing systems, like most physiological processes, cannot escape the effects of aging. With age, humans experience decreased duration and quality of sleep. Aged mice exhibit decreased amplitude and increased fragmentation of the activity rhythm, and lengthened circadian free-running period in both light-dark (LD) and constant dark (DD) conditions. Several studies have shown that aging impacts neural activity rhythms in the central circadian clock in the suprachiasmatic nucleus (SCN). However, evidence for age-related disruption of circadian oscillations of clock genes in the SCN has been equivocal. We hypothesized that daily exposure to LD cycles masks the full impact of aging on molecular rhythms in the SCN. We performed ex vivo bioluminescent imaging of cultured SCN slices of young and aged PER2::luciferase knock-in (PER2::LUC) mice housed under LD or prolonged DD conditions. Under LD conditions, the amplitude of PER2::LUC rhythms differed only slightly between SCN explants from young and aged animals; under DD conditions, the PER2::LUC rhythms of aged animals showed markedly lower amplitudes and longer circadian periods than those of young animals. Recordings of PER2::LUC rhythms in individual SCN cells using an electron multiplying charge-coupled device camera revealed that aged SCN cells showed longer circadian periods and that the rhythms of individual cells rapidly became desynchronized. These data suggest that aging degrades the SCN circadian ensemble, but that recurrent LD cycles mask these effects. We propose that these changes reflect a decline in pacemaker robustness that could increase vulnerability to environmental challenges, and partly explain age-related sleep and circadian disturbances.
\end{abstract}

Key words: aging; imaging; PER2::Iuciferase; suprachiasmatic nucleus

\section{Significance Statement}

It is becoming increasingly evident that aging impacts the neural activity rhythms in the central circadian clock in the SCN. However, evidence for age-related disruption of circadian oscillations of clock genes in the SCN has been equivocal. Our data indicate that, at the population level, aging lengthens the free-running period and attenuates the amplitude of population-based PER2::luciferase knock-in rhythms in the SCN. At the single-cell level, aging lengthens the period and reduces the synchrony of single-cell oscillations without reducing their amplitude. These findings were observed in mice housed in prolonged conditions of constant darkness. These data suggest that light-dark cycles mask the effects of aging on SCN cellular clocks and that aging may increase the vulnerability of the SCN circadian ensemble. 


\section{Introduction}

In mammals, daily behavioral and physiological rhythms are generated by a complex endogenous timing system involving cell-, tissue-, and organ-level mechanisms (Mohawk et al., 2012). The central circadian pacemaker, the suprachiasmatic nucleus (SCN) in the hypothalamus, is entrained by environmental lightdark (LD) cycles via photosensitive retinal ganglion cells. The SCN synchronizes the rhythms of many other brain regions, along with peripheral tissues, via neural and humoral factors (Welsh et al., 2010; LeGates et al., 2014). Circadian rhythms are generated within mammalian cells by interlocking transcriptional-translational feedback loops involving a family of clock genes (Partch et al., 2014). Briefly, transcription of Period (Per) and Cryptochrome (Cry) is driven by a complex of basic helix-loophelix transcriptional factors, including circadian locomotor output cycles kaput (CLOCK) and Aryl hydrocarbon receptor nuclear translocator-like 1 (BMAL1), and repressed by PER protein-mediated negative feedback. The SCN comprises a heterogeneous population of cells that differ in endogenous period, pacemaking ability, and expression of clock genes and neuropeptides (Honma et al., 2012; Hastings et al., 2014). In the SCN, a large population of different cells is synchronized to produce a coherent, robust rhythm.

Circadian timing systems, like most physiological processes, cannot escape the effects of aging. Aging is commonly associated with changes in the quantity and quality of sleep, and with specific sleep disorders, including sleep episode fragmentation, in humans and other mammals (Bliwise, 1993; Turek et al., 1995; Van Someren, 2000). In rodents, aging induces changes in locomotor activity rhythms, including decreased amplitude, increased fragmentation, shortened or lengthened freerunning period, slower re-entrainment following LD cycle shifts, and altered light sensitivity (Pittendrigh and Daan, 1974; Turek et al., 1995; Zhang et al., 1996; Scarbrough et al., 1997; Valentinuzzi et al., 1997). The age-related decline in behavioral rhythmicity can be partially reversed by implanting fetal SCN tissue into the third ventricle of aged animals (Van Reeth et al., 1994; Viswanathan and Davis, 1995; Cai et al., 1997; Li and Satinoff, 1998), indi-

Received June 1, 2015; accepted August 22, 2015; First published August 27, 2015.

${ }^{1}$ The authors declare no competing financial interests.

${ }^{2}$ Author contributions: T.J.N., W.N., C.S.C., and G.D.B. designed research; T.J.N. and T.K. performed research; T.J.N., W.N., I.T.T., and T.I. analyzed data; T.J.N., W.N., I.T.T., T.K., C.S.C., and G.D.B. wrote the paper..

${ }^{3}$ This work was supported by JSPS KAKENHI Grants 24790238 (T.J.N.), 26860160 (T.J.N.), and 26462809 (W.N.).

Correspondence should be addressed to either of the following: Takahiro J. Nakamura, Department of Life Sciences, School of Agriculture, Meiji University, 1-1-1 Higashimita, Taka-ku, Kanagawa, Kawasaki 214-8571, E-mail: takahiro@meiji.ac.jp; or Wataru Nakamura, Laboratory of Oral Chronobiology, Graduate School of Dentistry, Osaka University, 1-8 Yamadaoka, Suita, Osaka 565-0871, Japan, E-mail: wataru@dent.osaka-u.ac.jp.

DOI:http://dx.doi.org/10.1523/ENEURO.0064-15.2015

Copyright (C) 2015 Nakamura et al.

This is an open-access article distributed under the terms of the Creative Commons Attribution 4.0 International, which permits unrestricted use, distribution and reproduction in any medium provided that the original work is properly attributed. cating that the SCN plays an important role in age-related behavioral changes.

Several studies have examined the effects of aging on rhythmic expression of clock genes in the SCN, with conflicting results (Asai et al., 2001; Yamazaki et al., 2002; Kolker et al., 2003, 2004; Wyse and Coogan, 2010; Nakamura et al., 2011). Some studies have found evidence of age-related disruption of Bmal1 and Clock (Kolker et al., 2003; Wyse and Coogan, 2010), but most have reported that clock genes, such as Per genes, remain unaltered in aged animals (Asai et al., 2001; Yamazaki et al., 2002; Kolker et al., 2004; Davidson et al., 2008; Nakamura et al., 2011; Sellix et al., 2012). For example, Asai et al. (2001) measured expressions of Per1, Per2, and Cry 1 in the SCN and found that the waveforms of transcript rhythmicity were identical in aged (22- to 26month-old) rats and young (2- to 3-month-old) rats. Similarly, an ex vivo study (Yamazaki et al., 2002), which measured free-running rhythms in the Per1-luciferase (Per1-luc) rat model, confirmed that the waveforms of Per1 rhythmicity were identical in young (2-month-old) animals and aged (24- to 26-month-old) animals, although the free-running circadian period was shorter in aged animals. Therefore, with the exception of Bmal1 and Clock, there is little evidence that aging impacts the expression of clock genes, although a substantial agerelated impact on behavioral rhythmicity has been observed.

In an effort to understand the minimal impact of aging on the rhythms of key mammalian clock genes, we considered whether entrainment to LD cycles might mask some age-induced deficiencies of molecular clocks. We hypothesized that any lack of robustness in SCN oscillators in aged animals would more likely be revealed under free-running conditions in the absence of LD cycles, which would likely boost the amplitude of molecular rhythms and help maintain interoscillator synchrony. The effects of aging on clock genes in the SCN have previously been examined (Asai et al., 2001; Yamazaki et al., 2002; Kolker et al., 2003, 2004; Wyse and Coogan, 2010; Nakamura et al., 2011), but animals were housed under LD cycles or only briefly held in constant dark (DD) conditions. In the present study, we performed ex vivo bioluminescent imaging of cultured SCN slices of young and aged PER2::luciferase knock-in (PER2::LUC) mice housed in prolonged DD conditions (10 d). We observed the effects of aging on PER2::LUC oscillations in the SCN population, and we recorded PER2 oscillations at the single-cell level using an electron-multiplying (EM) charge-coupled device (CCD) camera. Mathematical analysis of the PER2 cellular oscillations revealed a longer circadian periodicity and desynchronized cellular rhythms in the aged SCN.

\section{Materials and Methods}

\section{Animals}

Male heterozygous PER2::LUC mice (C57BL/6J background; http://jaxmice.jax.org/strain/006852.html) were obtained from The Jackson Laboratory and bred for use in these experiments. Animals were classified into young 
and aged groups, and were housed separately until they reached the age for experimentation. Animals were maintained under controlled environmental conditions (temperature, $22 \pm 2^{\circ} \mathrm{C}$; LD cycle, $12 \mathrm{~h}$ light: $12 \mathrm{~h}$ dark, 100-300 lux at the bottom of the cage) with food and water available ad libitum. All animal procedures were performed according to the regulations of University of California Los Angeles Institutional Animal Care and Use Committee.

\section{Real-time monitoring of bioluminescence by photomultiplier tube}

Young (3- to 5- month-old $n=10$ ) and aged (13- to 15month-old $n=10$ ) PER2::LUC mice were used in this experiment. Upon reaching the age of experimentation, animals were individually housed; each cage contained a running wheel. Locomotor activity was measured as running wheel revolutions recorded in 1 min bins and analyzed with ClockLab Software (Actimetrics). Half of the young and aged mice were kept under a normal $12 \mathrm{~h}$ light: $12 \mathrm{~h}$ dark LD cycle (light-on time, 6:00 A.M.) for at least 2 weeks, and then the animals were killed at zeitgeber time (ZT) $10-11$ (ZT12 is defined as the time of lights off). The remaining young and aged animals were kept in DD for 10 d with monitoring of their wheel-running activities. The time of activity onset was calculated for individual animals on the day before the sampling and then they were killed in a dark room with dim red light ( $<1 \mathrm{lux}$ ) at circadian time (CT) 10-11 (CT12 is defined as the time of activity onset). The time of day, at which we harvested the tissue and cultured it, has little effect on its subsequent phase.

Bioluminescence monitoring was performed according to previously reported procedures (Yamazaki et al., 2002; Yoo et al., 2004; Savelyev et al., 2011). The brain of each mouse was removed, placed in chilled HBSS, and sliced in the coronal plane on a Microslicer (Dosaka EM) at a thickness of $300 \mu \mathrm{m}$. The bilateral SCN and a minimum of surrounding tissue were isolated from the slice using scalpels. The explants were placed in a LumiCycle equipped with photomultiplier tubes (PMTs; Actimetrics) and kept inside a light-tight $36.5^{\circ} \mathrm{C}$ environmental chamber. Recordings were started at ZT12 or CT12 for LDhoused mice and DD-housed mice, respectively. The bioluminescence signal was counted in 1 min bins every 10 min for at least $6 \mathrm{~d}$ without changing the media. The data were detrended by subtraction of the $24 \mathrm{~h}$ running average from the raw data and then smoothed with a $2 \mathrm{~h}$ running average (Origin Lab Software). The peak phase was set at the highest point of the smoothed data in each cycle. The amplitude was determined using the highest and lowest points of each cycle.

\section{EM-CCD camera recording of bioluminescence in individual SCN cells}

Young (3- to 5- month-old; $n=6$ ) and aged (20- to 24month-old; $n=6$ ) mice were used in this experiment. Animals were transferred to DD conditions for $10 \mathrm{~d}$. SCN explants were prepared using the procedure described for PMT recording. The SCN slices were kept in a lighttight $36.5^{\circ} \mathrm{C}$ environmental chamber and imaged using an ImagEM EM-CCD camera (Hamamatsu Photonics; frame rate, 32 frames/s; EM gain, 1200; objective lens; UPlanSApo 10×; numerical aperture, 0.40; Olympus). The bioluminescence images were stored as consecutive $50 \mathrm{~s}$ summed images every 1 min for $5 \mathrm{~d}$ (7200 images), with recording starting at $\mathrm{CT} 12$. One hundred twenty-eight images were averaged to produce a series of $60 \mathrm{~min}$ sampling images (AQUACOSMOS Software; Hamamatsu Photonics). Fifty cells in the SCN were randomly selected from a single image as regions of interest (ROIs). In the ROIs, brightness values were measured and tracked for all 120 images.

\section{Data analysis for single SCN cell monitoring}

To quantify the phase and amplitude of the cellular rhythms, bioluminescence signals extracted from the ROls of 120 images were analyzed using standard techniques. From simultaneous measurements of 50 cellular signals $\left\{x_{i}(t): t=1,2 \ldots, 120 ; i=1,2 . \ldots, 50\right\}$, the acrophases were obtained as follows. First, at time $t$, phase $\theta_{i}(t)$ of the ith cell was determined by Cosinor's method (Halberg et al., 1967). Namely, the bioluminescence signal $\left\{x_{i}(s): s=t-14, \ldots, t+14\right\}$ of the ith cell in the time interval from $s=t-14 \mathrm{~h}$ to $s=t+14 \mathrm{~h}$ was fitted to a cosine function $a_{i}(\mathrm{t})^{*} \cos \left(2 \pi\left(s+\theta_{i}(t)\right) / 24\right)$, where the oscillation period was fixed to $24 \mathrm{~h} ; a_{i}(t)$ represents the oscillation amplitude. The estimated phase $\theta_{i}(t)$ was considered reliable when the coefficient of determination was $>0.8$. The initial transient and final decaying portions were removed from the $120 \mathrm{~h}$ recordings, and the phase $\theta_{i}(t)$ was obtained for the time interval from $t=27 \mathrm{~h}$ to $t=98$ h. Next, with respect to the mean bioluminescence signal $\left\{1 / 50 \sum_{i=1}^{50} x_{i}(s): s=t-14, \cdots, t+14\right\}$, which was obtained by averaging the measurement across all 50 cells, the corresponding mean phase $\bar{\theta}(t)$ was determined in the same manner as for individual cells. By subtracting the mean phase $\bar{\theta}(t)$, the acrophase was obtained for each cell, as $\varphi_{i}(t)=\theta_{i}(t)-\bar{\theta}(t)$. To determine the level of synchrony among the 50 cells in each slice, the SD of the 50 acrophases was calculated. An alternative index for measuring synchrony (Bernard et al., 2007) yielded essentially identical results, indicating that the obtained result was not sensitive to the choice of the synchronization quantity. To measure the cellular amplitude, the coefficients $\left\{a_{i}(t): i=1,2, \ldots, 50\right\}$ determined in the Cosinor's analysis of the cellular signals were used. The time sequence of the amplitudes was then normalized as $\tilde{a}_{i}$ $(t)=a_{i}(t) / a_{i}(1)$, which sets the initial amplitude at unity. For each slice, the SD of the 50 cellular amplitudes was then calculated. To examine period lengthening, peak-to-peak periods were determined; peaks were located using the Cosinor's fitting of the cellular signals. The period ratio between the first and last cycles was then calculated.

\section{Statistical analysis}

In PMT recording and EM-CCD camera recording, datasets of phase and amplitude were analyzed by two-way repeated-measures ANOVA to examine the interaction effect of age and cycle (time) on the PER2::LUC rhythms. When the ANOVA detected significance, the post hoc Bonferroni method was used to examine the difference 

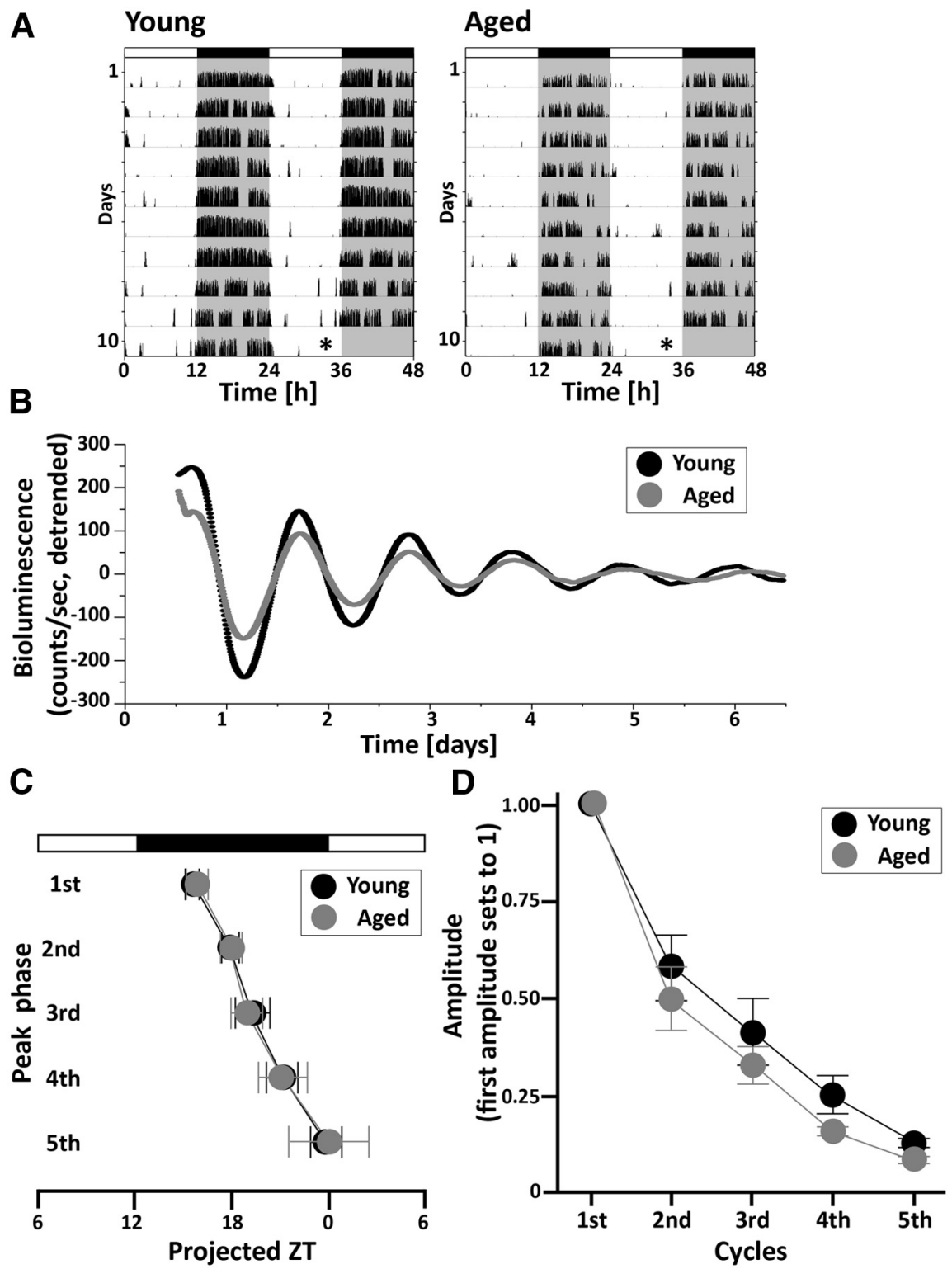

Figure 1. Effects of aging on PER2::LUC rhythms in SCN explants from mice maintained under LD cycles. A, Representative double-plotted actograms of wheel-running activity in young and aged PER2::LUC mice maintained under LD cycles. Lighting conditions are indicated at the top of the figure; open bars indicate light phases, and closed bars indicate dark phases. Asterisks indicate the timing of the killing of the animals. $\boldsymbol{B}$, Typical examples of the PER2::LUC rhythm of SCN explants from mice maintained under LD cycles, as measured by PMT. $\boldsymbol{C}$, Phase map of peak PER2::LUC rhythms in the SCN. Each point represents the average peak of PER2::LUC rhythms in each cycle, plotted relative to the LD cycle prior to the killing of the animals. $D$, Amplitude of PER2::LUC rhythms in the SCN. The amplitude of each oscillation was determined as the sum of the absolute values of the lowest and highest points (counts). Data are shown as the mean \pm SD. $n=5$ per group.

between young and aged groups at each time point. In EM-CCD camera recording, the difference in change in the free-running circadian period between young and aged groups was examined by unpaired Student's $t$ test. Statistical analysis was performed by IBM SPSS Statistics software. All results are presented as the mean \pm SD and were considered significant at $p<0.05$.

\section{Results}

First, we recorded bioluminescence rhythms in SCN explants from mice maintained under normal LD cycles (Fig. 1). The wheel-running activity of young and aged mice housed under LD cycles was monitored for at least $10 \mathrm{~d}$, and then the mice were killed at ZT10-11 (Fig. 1A). Both young and aged SCN tissue clearly showed circadian rhythms in PER2::LUC expression (Fig. 1B). We calculated the phase and amplitude of each cycle over time. Two-way repeated-measures ANOVA revealed no interaction between age and cycle at either phase $\left(p=0.966^{a}\right)$ or amplitude $\left(p=0.112^{\mathrm{b}}\right)$ data (Fig. $1 C, D$, Table 1).

Next, we recorded bioluminescence rhythms in SCN explants from mice maintained in DD (Fig. 2). The wheelrunning activity of young and aged mice in DD was mon- 
Table 1. Statistical table: results of two-way repeatedmeasures ANOVA for datasets of phase and amplitude in PMT recordings (Figs. 1C,D, 2C,D), and datasets of phase spread and amplitude in EM-CCD camera recordings (Fig. 3C,D)

\begin{tabular}{lllll}
\hline & & \multicolumn{2}{l}{ Interaction effect } \\
& & & \\
& & $F$ value $\times$ cycle (time)] & \\
a & Phase in LD & $F_{(4,32)}=0.141$ & 0.966 & ${ }^{1} \mathrm{C}$ \\
b & Amplitude in LD & $F_{(4,32)}=2.045$ & 0.112 & ${ }^{1} \mathrm{D}$ \\
c & Phase in DD & $F_{(4,32)}=11.328$ & $<0.001$ & ${ }^{2} \mathrm{C}$ \\
d Amplitude in DD & $F_{(4,32)}=12.377$ & $<0.001$ & ${ }^{2} \mathrm{D}$ \\
e & Phase spread in camera & $F_{(71,710)}=3.968$ & $<0.001$ & ${ }^{3} \mathrm{C}$ \\
$\mathrm{f}$ Amplitude in camera & $F_{(71,710)}=0.997$ & 0.488 & ${ }^{3} \mathrm{D}$ \\
\hline
\end{tabular}

itored for $10 \mathrm{~d}$, and the mice were then killed in the dark at CT10-11 (Fig. 2A). Both young and aged SCNs clearly showed circadian rhythms of PER2::LUC expression (Fig. 2B). Two-way repeated-measures ANOVA showed an interaction between age and cycle in the peak phases (Fig. $2 C$, Table $1 ; p<0.001^{\mathrm{C}}$ ). The phase differences gradually increased up to the fifth cycle [peak phase (CT); $16.13 \pm$ 1.24 and $18.03 \pm 0.63$ for the first cycle $\left(p<0.05^{9}\right) ; 17.53$ \pm 1.77 and $20.13 \pm 1.40$ for the second cycle $\left(p<0.05^{\mathrm{h}}\right)$; $18.43 \pm 2.34$ and $22.33 \pm 2.68$ for the third cycle $(p<$ $\left.0.05^{i}\right) ; 19.50 \pm 2.89$ and $24.80 \pm 2.31$ for the fourth cycle $(p<0.05) ; 19.7 \pm 2.67$ and $33.23 \pm 6.36$ for the fifth cycle $\left(p<0.01^{\mathrm{k}}\right)$ in young and aged SCNs ( $n=5$ per group), respectively; Fig. 2C, Table 2]. As indicated by the delayed peaks, the free-running period of PER2::LUC rhythm in aged SCNs was significantly longer than in young SCNs. Moreover, the amplitude was decreased by the aging; two-way repeated-measures ANOVA revealed a significant interaction between age and cycle in the amplitude data (Fig. 2D, Table 1; $p<0.001^{\mathrm{d}}$ ). Significant differences between young and aged groups were detected in the second to the fifth cycle [normalized amplitude (first cycle set to 1.00); $0.60 \pm 0.12$ and $0.35 \pm 0.07$ for the second cycle $\left(p<0.01^{\prime}\right) ; 0.39 \pm 0.10$ and $0.18 \pm$ 0.06 for the third cycle $\left(p<0.01^{\mathrm{m}}\right) ; 0.25 \pm 0.07$ and 0.10 \pm 0.03 for the fourth cycle $\left(p<0.01^{\mathrm{n}}\right) ; 0.15 \pm 0.06$ and $0.05 \pm 0.02$ for the fifth cycle $\left(p<0.01^{\circ}\right)$ in young and aged SCNs ( $n=5$ per group), respectively; Fig. $2 D$, Table 2].

Finally, we recorded PER2::LUC rhythms in individual SCN cells of aged mice using an EM-CCD camera. Young and aged mice were housed in DD for $10 \mathrm{~d}$ and then killed in darkness at CT10-11. The high resolution of the camera system allowed us to capture images of individual PER2:: LUC rhythms in SCN explants and to track individual cells over five cycles (120 h; Fig. $3 A, B$ ). Although PER2::LUC rhythms in individual cells showed clear circadian rhythms in both young and aged SCNs, aged cells gradually drifted out of phase with each other. To analyze this asynchrony, we calculated the SD of the acrophases of the 50 cells, as an index of their phase spread (Fig. 3C). The phase spread in young SCNs was $<1 \mathrm{~h}$ during the first cycle $(<24 \mathrm{~h})$ and remained $<1.5 \mathrm{~h}$ until the fifth cycle $(>96 \mathrm{~h}$ ). In contrast, the phase spread in aged SCNs showed a $1 \mathrm{~h}$ difference during the first cycle $(<24 \mathrm{~h})$ and gradually increased, until it exceeded $2 \mathrm{~h}$ by the fifth cycle ( $>96 \mathrm{~h})$. Two-way repeated-measures ANOVA indicated a significant interaction effect between age and time in the phase spread (Table 1; $p<0.001^{\mathrm{e}}$ ). Bonferroni post hoc comparison detected the difference between young and aged SCNs, and revealed that the difference became significant in recording time from 39 to $40 \mathrm{~h}$, and it remained significant after $44 \mathrm{~h}$ (Fig. 3C). We next calculated the amplitude of PER2::LUC rhythm in individual cells of SCN explants from young and aged mice over five cycles. In both age groups, the amplitude gradually decreased; two-way repeated-measures ANOVA revealed no significant interaction effect between age and time in the amplitudes (Fig. $3 D$, Table $1 ; p=0.488^{f}$ ). Finally, we calculated the changes in the free-running circadian period of individual SCN cells. The change in circadian period differed significantly between SCNs from young and aged mice [ratio of period change: $1.04 \pm 0.09$ and $1.20 \pm 0.14$ in SCNs from young and aged mice ( $n=6$ per group), respectively $(p<$ $0.05^{\mathrm{P}}$; ; Fig. 3E, Table 2].

\section{Discussion}

Aging profoundly alters circadian behavior and physiology. However, the molecular clockwork that underlies these circadian rhythms appears to be more resilient. For example, most studies of oscillations in Period genes have failed to detect substantial age-related decline. In our first experiment, we examined PER2::LUC rhythms in the SCN of mice housed under normal LD cycles. Under these conditions, we observed only a small difference between young and aged SCN explants in PER2::LUC amplitude, and no difference was observed in the peak phase (Fig. 1). These observations are consistent with a previous study that examined PER2::LUC mice using immunohistochemistry (Nakamura et al., 2011). Past work (Yamazaki et al., 2002) using a Per1-luc rat did find that aged SCN explants exhibited a shorter free-running period than those from young animals, without changes in waveform or amplitude. Other studies used in situ hybridization and immunohistochemistry techniques to characterize subtle age-related changes in the rhythmic expression of Per genes (Asai et al., 2001; Kolker et al., 2003, 2004; Nakamura et al., 2011). Notably, Clock and Bmal1 expression was reduced in SCN tissue of aged hamsters that were housed under LD cycles and killed after $3 \mathrm{~d}$ in DD (Kolker et al., 2003). A more recent study reported a reduction in BMAL1 and CLOCK proteins in the SCN of old mice (Chang and Guarente, 2013). These data may indicate that the positive activators (Clock and $B$ mal1) of the molecular clock are more strongly influenced by aging than the negative-feedback elements ( $P e r$ and Cry).

It is well established that Per1 and Per2 are induced in the SCN after light exposure during the night (Shearman et al., 1997; Shigeyoshi et al., 1997); thus, it is possible that daily light exposure masks the true impact of aging on PER2::LUC rhythms in the SCN. In support of this hypothesis, we found that both the amplitude and peak phase of PER2::LUC rhythms in the SCN of mice housed in DD conditions for $10 \mathrm{~d}$ (DD-housed mice) were influ- 

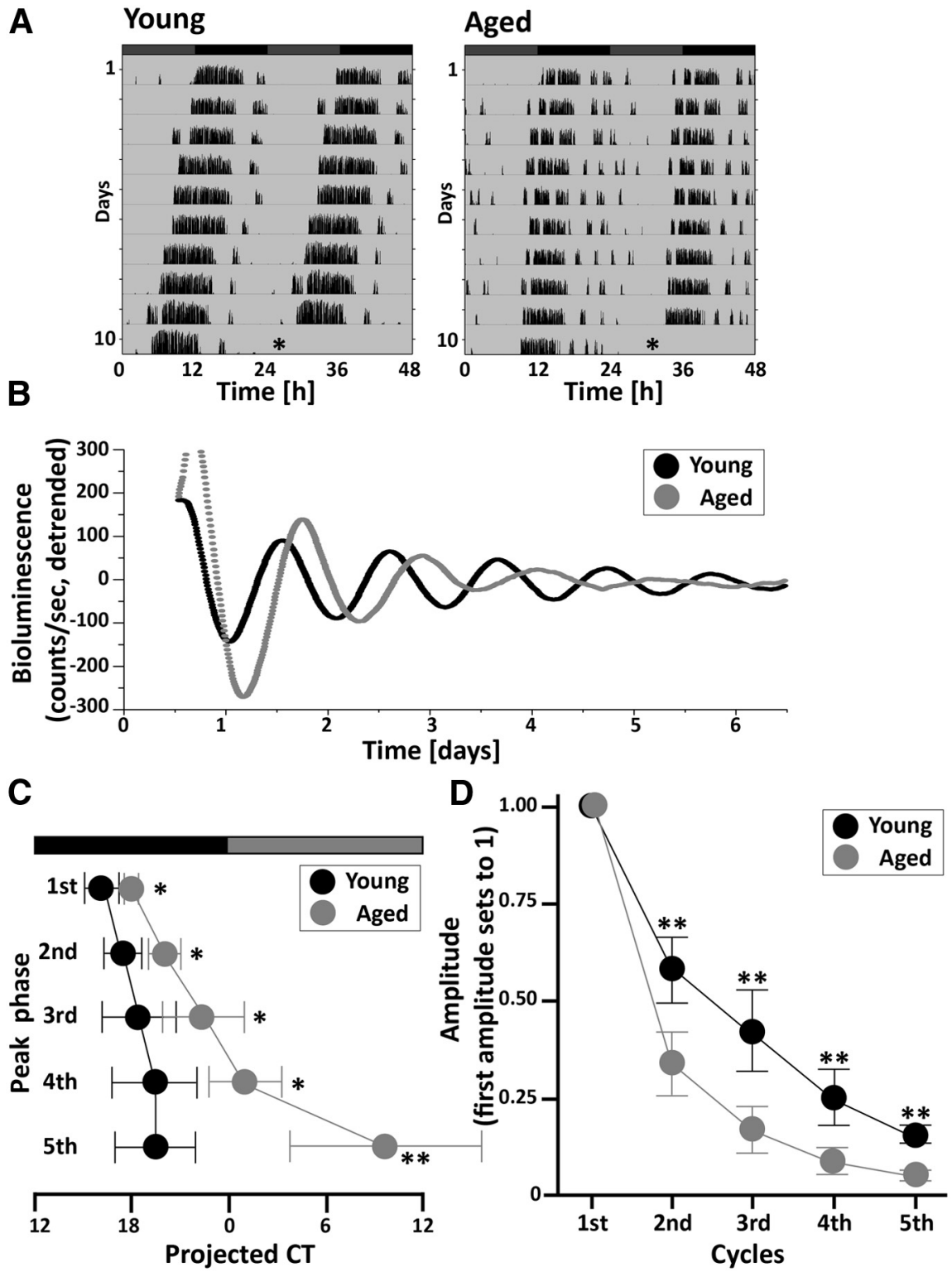

Figure 2. Effects of aging on PER2::LUC rhythms in SCN explants from mice maintained in DD. $\boldsymbol{A}$, Representative double-plotted actograms of wheel-running activity in young and aged PER2::LUC mice maintained in DD. Asterisks indicate the timing of the killing of the animals. B, Typical examples of PER2::LUC rhythms of SCN explants from mice maintained in DD for 10 d, as measured by PMT. $\boldsymbol{C}$, Phase map of peak PER2::LUC rhythms in the SCN. Each point represents the average peak of PER2::LUC rhythms in each cycle, plotted relative to the circadian time prior to the killing of the animals. $D$, Amplitude of PER2::LUC rhythms in the SCN. The amplitude of each oscillation was determined as the sum of the absolute value of the lowest and highest points (counts). Data are shown as the mean \pm SD. $n=5$ per group. $* p<0.05, * * p<0.01$ for young vs. aged animals (Bonferroni post hoc comparison).

enced by aging. The PMT allows us to measure the summed response of the SCN circuit. We observed a lengthened free-running period and an attenuated waveform in PER2::LUC rhythms in SCN explants of aged DD-housed mice (Fig. 2). We emphasize that the critical difference between the present study and the previous studies (Asai et al., 2001; Yamazaki et al., 2002; Kolker et al., 2003, 2004; Nakamura et al., 2011) is the use of an LD environment. Previous studies did not detect agerelated changes in rhythmic expression of Per1 and Per2 genes (Asai et al., 2001; Yamazaki et al., 2002; Kolker et al., 2003, 2004; Nakamura et al., 2011) in animals housed in LD cycles or immediately after release to the DD condition (e.g., 2 or $3 \mathrm{~d}$ in DD). In contrast, our DD-housed mice were not exposed to light for at least 10 d prior to preparation of the slice cultures.

In our experiment on young mice, the free-running period of PER2::LUC rhythms in SCN explants of the LDhoused mice was longer than that of the DD-housed mice. This indicates that the LD condition lengthened the free- 
Table 2. Statistical table for pairwise comparisons

\begin{tabular}{lllll}
\hline & Data structure & Type of test & $p$ value & Figure \\
$\mathrm{g}$ & Normally distributed & Bonferroni & 0.016 & ${ }^{2} \mathrm{C}$ \\
$\mathrm{h}$ & Normally distributed & Bonferroni & 0.033 & ${ }^{2} \mathrm{C}$ \\
$\mathrm{i}$ & Normally distributed & Bonferroni & 0.040 & ${ }^{2} \mathrm{C}$ \\
$\mathrm{j}$ & Normally distributed & Bonferroni & 0.012 & ${ }^{2} \mathrm{C}$ \\
$\mathrm{k}$ & Normally distributed & Bonferroni & 0.002 & ${ }^{2} \mathrm{C}$ \\
$\mathrm{l}$ & Normally distributed & Bonferroni & 0.003 & ${ }^{2} \mathrm{D}$ \\
$\mathrm{m}$ & Normally distributed & Bonferroni & 0.004 & ${ }^{2} \mathrm{D}$ \\
$\mathrm{n}$ & Normally distributed & Bonferroni & 0.003 & ${ }^{2} \mathrm{D}$ \\
$\mathrm{o}$ & Normally distributed & Bonferroni & 0.004 & ${ }^{2} \mathrm{D}$ \\
$\mathrm{p}$ & Normally distributed & $t$ test & 0.026 & ${ }^{3} \mathrm{E}$ \\
\hline
\end{tabular}

running period of the PER2::LUC rhythms. To measure the free-running period in the behavioral rhythm of mice, environmental factors, which may influence the rhythm, should be eliminated. For this reason, mice are usually maintained in DD conditions for the observation of their intrinsic rhythms. In the present study, we took the same approach to observe the effects of aging. Previous reports showed that aging lengthens the free-running period in C57BL/6J mice, which have the same background line of PER2::LUC mice (Turek et al., 1995). Moreover, the period length of the behavioral rhythm in these mice is known to be consistent with that of the SCN molecular rhythm (Liu et al., 2007). Taken together, these findings suggest that the elimination of light for $10 \mathrm{~d}$ reveals the intrinsic effect of aging on the free-running period of PER2::LUC rhythm in the SCN.

Next, we used camera recordings to examine the rhythms of individual neurons. In the camera recordings, we found that aging lengthened the free-running period of the PER2::LUC rhythms of individual SCN cells within the explant, but did not affect the amplitude (Fig. 3). Moreover, the single-cell analysis revealed that the phase of PER2::LUC rhythms in individual SCN cells became dissociated with age (Fig. 3). Considering the period length and the waveform separately, these data suggest that aging lengthens the period of PER2::LUC rhythms in individual SCN cells, which results in lengthening of the period in the entire SCN. In contrast, the attenuation of the waveform appears to be a population phenomenon due to the phase dissociation of the PER2::LUC rhythms among individual SCN cells. We used older aged animals (20- to 24- month-old) in the single-cell recordings than those we used (13- to 16- month-old) in PMT recordings to maximize our chances of seeing an impact of aging on single $\mathrm{SCN}$ cells. Several prior studies that examined the effect of aging on the rhythms of Per genes in the SCN (Asai et al., 2001; Yamazaki et al., 2002; Kolker et al., 2003, 2004) used relatively old animals (17- to 26- month-old) and did not detect age-related changes in rhythmic expression of Per1 and Per2 genes. In contrast, in the present study, the PMT recordings revealed an agerelated decline in PER2::LUC rhythms at the SCN population level even with middle-aged mice (13- to 16- month old). A recent behavioral analysis found that the freerunning period of 10-month-old mice was significantly longer than that of 3-month-old mice (Farajnia et al., 2012). Decline in the total amount of activity was also observed with the older mice. The changes in the freerunning period and the total amount of activity declined further with older mice (Farajnia et al., 2012). In addition, previous in vivo multiunit neuronal activity recordings in freely moving middle-aged (13-month-old) mice indicated that circadian rhythms of electrical activity in the SCN are already degraded by middle age (Nakamura et al., 2011). These previous studies as well as the present results suggest that the phase dissociation of the PER2::LUC rhythms among individual SCN cells is observed not only in aged (20- to 24-month-old) mice, but also in middleaged (13- to 16-month-old) mice, which we used for the PMT recordings.

In our PMT recordings of DD-housed mice, the initial peak of PER2::LUC rhythm in SCNs from aged mice was found to be higher than that in SCNs from young mice (Fig. 2). The camera recordings also indicated that the initial peak of PER2::LUC was well synchronized in individual cells of aged SCNs, relative to those of SCNs from young mice (Fig. 3). Culture preparation might have affected the phase of individual cells, although the SCNs of young PER2::LUC mice are not usually affected by culture preparation (Davidson et al., 2009). If intercellular coupling is weaker in SCNs from aged mice, the culture preparation might have a stronger effect on the synchronization of cellular clocks in individual SCN cells.

Although the present study suggests weaker intercellular couplings in aged SCNs, the mechanisms that underlie these age-related changes in the SCN are still unclear. The cellular oscillators within the SCN are coupled via neuropeptides (Welsh et al., 2010; Maywood et al., 2011), and there is evidence of age-related decline in the expression of key neuropeptides (Kawakami et al., 1997; Krajnak et al., 1998; Duncan et al., 2001; Aton and Herzog, 2005; Maywood et al., 2011). Furthermore, GABA is the major transmitter within the SCN network and prior work has shown that the number of GABAergic synaptic terminals in the SCN is diminished in old mice (Palomba et al., 2008). Physiological recordings have confirmed that GABAergic postsynaptic currents are reduced in amplitude and frequency in the aging SCN (Nygård et al., 2005; Farajnia et al., 2012). In vivo and in vitro experiments from several laboratories have shown that the electrical activity rhythms that characterize SCN physiology are also vulnerable to the effects of aging (Satinoff et al., 1993; Watanabe et al., 1995; Aujard et al., 2001; Nakamura et al., 2011; Farajnia et al., 2012). A reduction in electrical activity would be expected to reduce the release of peptides as well as GABA. Finally, in a recent study, patch-clamp recordings of SCN neurons in aged mice revealed that the circadian modulation of large-conductance $\mathrm{Ca}^{2+}$ activated $\mathrm{K}^{+}(\mathrm{BK})$ channel activity was lost because of a reduction in BK currents during the night (Farajnia et al., 2015). Thus, we favor the hypothesis that aging leads to changes in electrical activity, which, in turn, weaken intercellular coupling among SCN cells.

In summary, our data indicate that, at the population level, aging lengthens the free-running period and attenuates the amplitude of population-based PER2::LUC rhythms in the SCN. At the single-cell level, we found that 
A

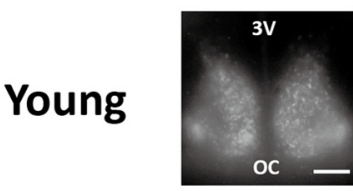

Aged

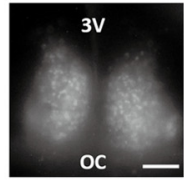

$30 \mathrm{~h}$
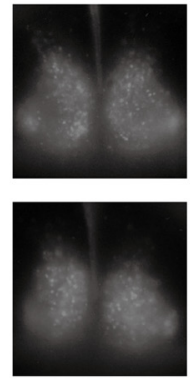

$42 \mathrm{~h}$
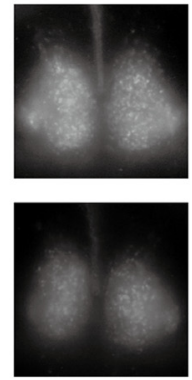

$108 \mathrm{~h}$
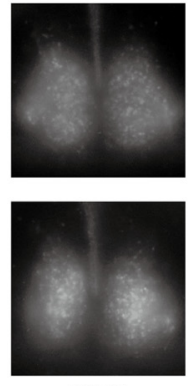

$120 \mathrm{~h}$

B

Young

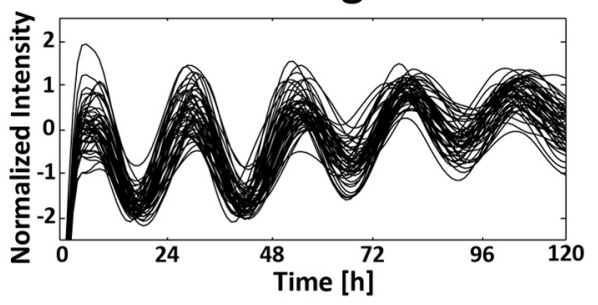

Aged
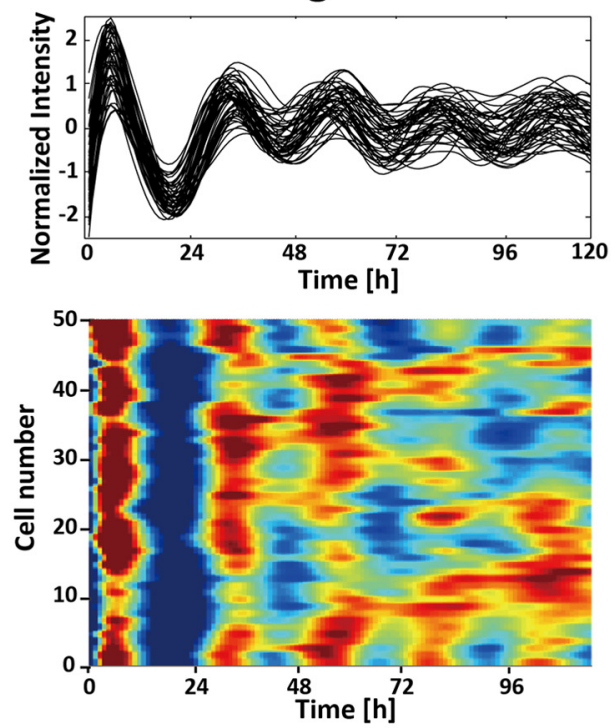

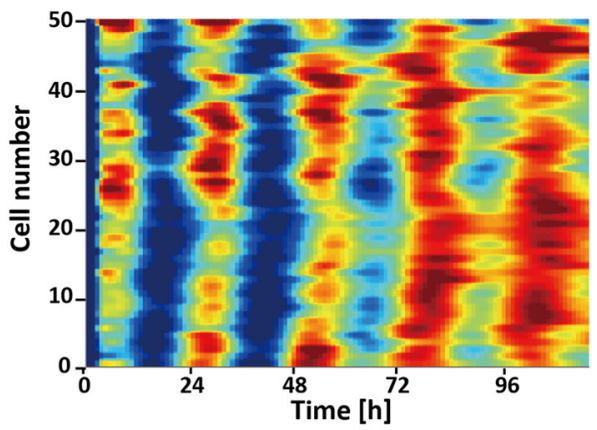

C

D

E
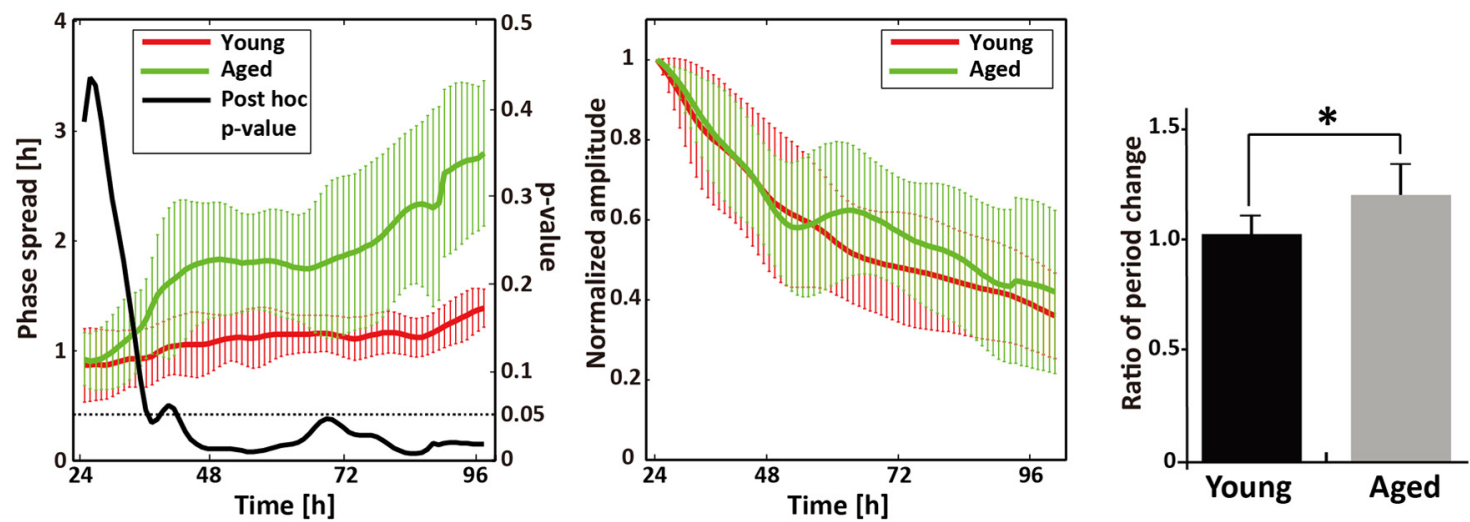

Figure 3. Effects of aging on PER2::LUC rhythms in SCN explants from mice maintained in DD. A, Representative images of PER2::LUC in SCN explants collected from young and aged mice maintained in DD for $10 \mathrm{~d}$, recorded by an EM-CCD camera at 30 , 42,108 , and $120 \mathrm{~h}$ after the start of recording. $\boldsymbol{B}$, Representative graphical (top) and raster (below) plots of PER2::LUC rhythms of individual cells in SCN explants of young and aged SCNs. C, $\boldsymbol{D}$, Phase spreads (C) and normalized amplitudes (D) of PER2::LUC rhythms averaged over young (red) and aged (green) SCNs are shown over five cycles. $\boldsymbol{E}$, Ratios of free-running circadian period change from the first to the fifth cycle of PER2::LUC rhythms in 50 individual SCN cells are shown. Data are shown as the mean \pm SD. $n=6$ per group. $* p<0.05$ ( $t$ test). Scale bar, $100 \mu \mathrm{m}$.

aging lengthens the period and reduces the synchrony of single-cell oscillations without reducing their amplitude. Under a robust LD cycle, these deficits are masked; thus, our research is consistent with the suggestion that exposure to a robust LD cycle will help to maintain the strength of circadian oscillations in elderly people. Indeed, there is 
already some evidence that reinforcing the circadian system using light can improve daytime alertness and sleep quality in aged individuals (Mishima et al., 2001; Riemersma-van der Lek et al., 2008; Lieverse et al., 2011; Friedman et al., 2012; Royer et al., 2012). However, other studies have observed only small changes in sleep as a result of light therapy (Ancoli-Israel et al., 2002; Dowling et al., 2008; Friedman et al., 2009). The design of many of these studies should be re-evaluated in the light of our current understanding of the light-input pathways of the circadian system and, in particular, the importance of the photopigment melanopsin (LeGates et al., 2014). Although aging in mice may well differ from aging in humans, our analysis reveals a hidden vulnerability in the molecular clockwork that indicates that the aging circadian system is more sensitive to environmental challenges than previously suspected. We speculate that this vulnerability may play a role in the sleep and circadian dysfunction that is so common in the aging population. If correct, these findings reinforce the importance of living in a temporally structured environment.

\section{References}

Ancoli-Israel S, Martin JL, Kripke DF, Marler M, Klauber MR (2002) Effect of light treatment on sleep and circadian rhythms in demented nursing home patients. J Am Geriatr Soc 50:282-289. Medline

Asai M, Yoshinobu Y, Kaneko S, Mori A, Nikaido T, Moriya T, Akiyama M, Shibata S (2001) Circadian profile of Per gene mRNA expression in the suprachiasmatic nucleus, paraventricular nucleus, and pineal body of aged rats. J Neurosci Res 66:1133-1139. Medline

Aton SJ, Herzog ED (2005) Come together, right. . .now: synchronization of rhythms in a mammalian circadian clock. Neuron 48:531534. CrossRef Medline

Aujard F, Herzog ED, Block GD (2001) Circadian rhythms in firing rate of individual suprachiasmatic nucleus neurons from adult and middle-aged mice. Neuroscience 106:255-261. Medline

Bernard S, Gonze D, Cajavec B, Herzel H, Kramer A (2007) Synchronization-induced rhythmicity of circadian oscillators in the suprachiasmatic nucleus. PLoS Comput Biol 3:e68. CrossRef Medline

Bliwise DL (1993) Sleep in normal aging and dementia. Sleep 16:4081. Medline

Cai A, Scarbrough K, Hinkle DA, Wise PM (1997) Fetal grafts containing suprachiasmatic nuclei restore the diurnal rhythm of $\mathrm{CRH}$ and POMC mRNA in aging rats. Am J Physiol 273:R1764-R1770. Medline

Chang HC, Guarente L (2013) SIRT1 mediates central circadian control in the SCN by a mechanism that decays with aging. Cell 153:1448-1460. CrossRef Medline

Davidson AJ, Castanon-Cervantes O, Leise TL, Molyneux PC, Harrington ME (2009) Visualizing jet lag in the mouse suprachiasmatic nucleus and peripheral circadian timing system. Eur $\mathrm{J}$ Neurosci 29:171-180. CrossRef Medline

Davidson AJ, Yamazaki S, Arble DM, Menaker M, Block GD (2008) Resetting of central and peripheral circadian oscillators in aged rats. Neurobiol Aging 29:471-477. CrossRef Medline

Dowling GA, Burr RL, Van Someren EJ, Hubbard EM, Luxenberg JS, Mastick J, Cooper BA (2008) Melatonin and bright-light treatment for rest-activity disruption in institutionalized patients with Alzheimer's disease. J Am Geriatr Soc 56:239-246. CrossRef

Duncan MJ, Herron JM, Hill SA (2001) Aging selectively suppresses vasoactive intestinal peptide messenger RNA expression in the suprachiasmatic nucleus of the Syrian hamster. Brain Res Mol Brain Res 87:196-203. Medline
Farajnia S, Michel S, Deboer T, vanderLeest HT, Houben T, Rohling JH, Ramkisoensing A, Yasenkov R, Meijer JH (2012) Evidence for neuronal desynchrony in the aged suprachiasmatic nucleus clock. J Neurosci 32:5891-5899. CrossRef Medline

Farajnia S, Meijer JH, Michel S (2015) Age-related changes in largeconductance calcium-activated potassium channels in mammalian circadian clock neurons. Neurobiol Aging 36:2176-2183. CrossRef Medline

Friedman L, Spira AP, Hernandez B, Mather C, Sheikh J, AncoliIsrael S, Yesavage JA, Zeitzer JM (2012) Brief morning light treatment for sleep/wake disturbances in older memory-impaired individuals and their caregivers. Sleep Med 13:546-549. CrossRef Medline

Friedman L, Zeitzer JM, Kushida C, Zhdanova I, Noda A, Lee T, Schneider B, Guilleminault C, Sheikh J, Yesavage JA (2009) Scheduled bright light for treatment of insomnia in older adults. $J$ Am Geriatr Soc 57:441-452. CrossRef Medline

Halberg F, Tong YL, Johnson EA (1967) Circadian system phase-an aspect of temporal morphology; procedures and illustrative examples. In: The cellular aspects of biorhythms (von Mayersbach, $\mathrm{H}$., ed), pp 20-48. Berlin: Springer Berlin Heidelberg.

Hastings MH, Brancaccio M, Maywood ES (2014) Circadian pacemaking in cells and circuits of the suprachiasmatic nucleus. $J$ Neuroendocrinol 26:2-10. CrossRef Medline

Honma S, Ono D, Suzuki Y, Inagaki N, Yoshikawa T, Nakamura W, Honma K (2012) Suprachiasmatic nucleus: cellular clocks and networks. Prog Brain Res 199:129-141. CrossRef Medline

Kawakami F, Okamura H, Tamada Y, Maebayashi Y, Fukui K, Ibata $Y$ (1997) Loss of day-night differences in VIP mRNA levels in the suprachiasmatic nucleus of aged rats. Neurosci Lett 222:99-102. Medline

Kolker DE, Fukuyama H, Huang DS, Takahashi JS, Horton TH, Turek FW (2003) Aging alters circadian and light-induced expression of clock genes in golden hamsters. J Biol Rhythms 18:159-169. Medline

Kolker DE, Vitaterna MH, Fruechte EM, Takahashi JS, Turek FW (2004) Effects of age on circadian rhythms are similar in wild-type and heterozygous Clock mutant mice. Neurobiol Aging 25:517523. CrossRef Medline

Krajnak K, Kashon ML, Rosewell KL, Wise PM (1998) Aging alters the rhythmic expression of vasoactive intestinal polypeptide mRNA but not arginine vasopressin mRNA in the suprachiasmatic nuclei of female rats. J Neurosci 18:4767-4774.

LeGates TA, Fernandez DC, Hattar S (2014) Light as a central modulator of circadian rhythms, sleep and affect. Nat Rev Neurosci 15:443-454. CrossRef Medline

$\mathrm{Li} \mathrm{H}$, Satinoff E (1998) Fetal tissue containing the suprachiasmatic nucleus restores multiple circadian rhythms in old rats. Am J Physiol 275:R1735-R1744. Medline

Lieverse R, Van Someren EJ, Nielen MM, Uitdehaag BM, Smit JH, Hoogendijk WJ (2011) Bright light treatment in elderly patients with nonseasonal major depressive disorder: a randomized placebocontrolled trial. Arch Gen Psychiatry 68:61-70. CrossRef Medline

Liu AC, Welsh DK, Ko CH, Tran HG, Zhang EE, Priest AA, Buhr ED, Singer O, Meeker K, Verma IM, Doyle FJ 3rd, Takahashi JS, Kay SA (2007) Intercellular coupling confers robustness against mutations in the SCN circadian clock network. Cell 129:605-616. CrossRef Medline

Maywood ES, Chesham JE, O'Brien JA, Hastings MH (2011) A diversity of paracrine signals sustains molecular circadian cycling in suprachiasmatic nucleus circuits. Proc Natl Acad Sci U S A 108:14306-14311. CrossRef Medline

Mishima K, Okawa M, Shimizu T, Hishikawa Y (2001) Diminished melatonin secretion in the elderly caused by insufficient environmental illumination. J Clin Endocrinol Metab 86:129-134. CrossRef Medline

Mohawk JA, Green CB, Takahashi JS (2012) Central and peripheral circadian clocks in mammals. Annu Rev Neurosci 35:445-462. CrossRef Medline 
Nakamura TJ, Nakamura W, Yamazaki S, Kudo T, Cutler T, Colwell CS, Block GD (2011) Age-related decline in circadian output. J Neurosci 31:10201-10205. CrossRef Medline

Nygård M, Hill RH, Wikström MA, Kristensson K (2005) Age-related changes in electrophysiological properties of the mouse suprachiasmatic nucleus in vitro. Brain Res Bull 65:149-154. CrossRef Medline

Palomba M, Nygård M, Florenzano F, Bertini G, Kristensson K, Bentivoglio M (2008) Decline of the presynaptic network, including GABAergic terminals, in the aging suprachiasmatic nucleus of the mouse. J Biol Rhythms 23:220-231. CrossRef Medline

Partch CL, Green CB, Takahashi JS (2014) Molecular architecture of the mammalian circadian clock. Trends Cell Biol 24:90-99. CrossRef Medline

Pittendrigh CS, Daan S (1974) Circadian oscillations in rodentssystematic increase of their frequency with age. Science 186:548550. Medline

Riemersma-van der Lek RF, Swaab DF, Twisk J, Hol EM, Hoogendijk WJ, Van Someren EJ (2008) Effect of bright light and melatonin on cognitive and noncognitive function in elderly residents of group care facilities: a randomized controlled trial. JAMA 299:2642-2655. CrossRef Medline

Royer M, Ballentine NH, Eslinger PJ, Houser K, Mistrick R, Behr R, Rakos K (2012) Light therapy for seniors in long term care. J Am Med Dir Assoc 13:100-102. CrossRef Medline

Satinoff E, Li H, Tcheng TK, Liu C, McArthur AJ, Medanic M, Gillette MU (1993) Do the suprachiasmatic nuclei oscillate in old rats as they do in young ones? Am J Physiol 265:R1216-R1222. Medline

Savelyev SA, Larsson KC, Johansson AS, Lundkvist GB (2011) Slice preparation, organotypic tissue culturing and luciferase recording of clock gene activity in the suprachiasmatic nucleus. J Vis Exp (48):e2439.

Scarbrough K, Losee-Olson S, Wallen EP, Turek FW (1997) Aging and photoperiod affect entrainment and quantitative aspects of locomotor behavior in Syrian hamsters. Am J Physiol 272:R1219R1225. Medline

Sellix MT, Evans JA, Leise TL, Castanon-Cervantes O, Hill DD, DeLisser P, Block GD, Menaker M, Davidson AJ (2012) Aging differentially affects the re-entrainment response of central and peripheral circadian oscillators. J Neurosci 32:16193-16202. CrossRef

Shearman LP, Zylka MJ, Weaver DR, Kolakowski LF Jr, Reppert SM (1997) Two period homologs: circadian expression and photic regulation in the suprachiasmatic nuclei. Neuron 19:1261-1269. Medline
Shigeyoshi Y, Taguchi K, Yamamoto S, Takekida S, Yan L, Tei H, Moriya T, Shibata S, Loros JJ, Dunlap JC, Okamura H (1997) Light-induced resetting of a mammalian circadian clock is associated with rapid induction of the mPer1 transcript. Cell 91:10431053. Medline

Turek FW, Penev P, Zhang Y, van Reeth O, Zee P (1995) Effects of age on the circadian system. Neurosci Biobehav Rev 19:53-58. CrossRef

Valentinuzzi VS, Scarbrough K, Takahashi JS, Turek FW (1997) Effects of aging on the circadian rhythm of wheel-running activity in C57BL/6 mice. Am J Physiol 273:R1957-R1964. Medline

Van Reeth O, Zhang Y, Zee PC, Turek FW (1994) Grafting fetal suprachiasmatic nuclei in the hypothalamus of old hamsters restores responsiveness of the circadian clock to a phase shifting stimulus. Brain Res 643:338-342. Medline

Van Someren EJ (2000) Circadian and sleep disturbances in the elderly. Exp Gerontol 35:1229-1237.

Viswanathan N, Davis FC (1995) Suprachiasmatic nucleus grafts restore circadian function in aged hamsters. Brain Res 686:10-16. Medline

Watanabe A, Shibata S, Watanabe S (1995) Circadian rhythm of spontaneous neuronal activity in the suprachiasmatic nucleus of old hamster in vitro. Brain Res 695:237-239. Medline

Welsh DK, Takahashi JS, Kay SA (2010) Suprachiasmatic nucleus: cell autonomy and network properties. Annu Rev Physiol 72:551577. CrossRef Medline

Wyse CA, Coogan AN (2010) Impact of aging on diurnal expression patterns of CLOCK and BMAL1 in the mouse brain. Brain Res 1337:21-31. CrossRef Medline

Yamazaki S, Straume M, Tei H, Sakaki Y, Menaker M, Block GD (2002) Effects of aging on central and peripheral mammalian clocks. Proc Natl Acad Sci U S A 99:10801-10806. CrossRef Medline

Yoo SH, Yamazaki S, Lowrey PL, Shimomura K, Ko CH, Buhr ED, Siepka SM, Hong HK, Oh WJ, Yoo OJ, Menaker M, Takahashi JS (2004) PERIOD2::LUCIFERASE real-time reporting of circadian dynamics reveals persistent circadian oscillations in mouse peripheral tissues. Proc Natl Acad Sci U S A 101:5339-5346. CrossRef Medline

Zhang Y, Kornhauser JM, Zee PC, Mayo KE, Takahashi JS, Turek FW (1996) Effects of aging on light-induced phase-shifting of circadian behavioral rhythms, fos expression and CREB phosphorylation in the hamster suprachiasmatic nucleus. Neuroscience 70:951-961. Medline 